\title{
Comparison of minimally invasive transspinous and open approaches for thoracolumbar intradural-extramedullary spinal tumors
}

\author{
Kunal P. Raygor, MD, Khoi D. Than, MD, Dean Chou, MD, and Praveen V. Mummaneni, MD \\ Department of Neurological Surgery, University of California, San Francisco, California
}

\begin{abstract}
OBJECT Spinal tumor resection has historically been performed via open approaches, although minimally invasive approaches have recently been found to be effective in small cohort series. The authors compare surgical characteristics and clinical outcomes of surgery in patients undergoing mini-open and open approaches for intradural-extramedullary tumor resection.
\end{abstract}

METHODS The authors retrospectively reviewed 65 consecutive intradural-extramedullary tumor resections performed at their institution from 2007 to 2014. Patients with cervical tumors or pathology demonstrating neurofibroma were excluded $(n=14)$. The nonparametric Mann-Whitney U-test and Pearson chi-square test were used to compare continuous and categorical variables, respectively. Statistical analyses were performed using SPSS, with significance set at $p<0.05$.

RESULTS Fifty-one thoracolumbar intradural-extramedullary tumor resections were included; 25 were performed via the minimally invasive transspinous approach. There were no statistically significant differences in age, sex, body mass index, preoperative American Spinal Injury Association (ASIA) score, preoperative symptom duration, American Society of Anesthesiologists (ASA) physical status class, tumor size, or tumor location. There was no statistically significant difference between groups with respect to the duration of the operation or extent of resection, but the mean estimated blood loss was significantly lower in the minimally invasive surgery (MIS) cohort (142 vs $320 \mathrm{ml}, \mathrm{p}<0.05)$. In each group, the 2 most common tumor pathologies were schwannoma and meningioma. There were no statistically significant differences in length of hospitalization, ASIA score improvement, complication rate, or recurrence rate. The mean duration of follow-up was 2 years for the MIS group and 1.6 years for the open surgery group.

CONCLUSIONS This is one of the largest comparisons of minimally invasive and open approaches to the resection of thoracolumbar intradural-extramedullary tumors. With well-matched cohorts, the minimally invasive transspinous approach appears to be as safe and effective as the open technique, with the advantage of significantly reduced intraoperative blood loss.

http://thejns.org/doi/abs/10.3171/2015.5.FOCUS15187

KEY WORDS minimally invasive surgery; intradural; extramedullary; spinal tumors

$\mathrm{S}$ PINAL tumors are exceedingly rare, with an incidence between 1 and 10 per 100,000 people..$^{3,5,10,14}$ Grosstotal resection, the treatment of choice for intradural-extramedullary neoplasms, has historically been performed via an open surgical technique using a posterior laminectomy or hemilaminectomy. These open approaches have led to excellent outcomes ${ }^{6}$ but are associated with more tissue injury and blood loss than newer, alternative techniques.

While a number of minimally invasive approaches have been described, we prefer the minimally invasive transspinous approach with a midline incision because it provides access to the entirety of the dorsal spinal cord. Here, we compare our continued experience with this approach

ABBREVIATIONS ASA = American Society of Anesthesiologists; ASIA = American Spinal Injury Association; EBL = estimated blood loss; LOS = length of stay; MIS = minimally invasive surgery; $\mathrm{PCA}=$ patient-controlled anesthesia.

SUBMITTED April 2, 2015. ACCEPTED May 14, 2015.

INCLUDE WHEN CITING DOI: 10.3171/2015.5.FOCUS15187.

DISCLOSURE Dr. Chou is a consultant for Orthofix, Globus Medical, and Medtronic Spine. Dr. Mummaneni is a consultant for Globus Medical; received honoraria from DePuy Spine, Globus, and AOSpine; receives royalties from DePuy Spine, Taylor and Francis/Quality Medical Publishing, Springer, and Thieme; and owns stock in Spinicity and Innovative Surgical Designs. 
to intradural-extramedullary spinal cord tumor resection with a standard, open laminectomy approach.

\section{Methods}

\section{Patient Selection and Data Collection}

Sixty-two patients undergoing 65 consecutive intradural spinal tumor resections were discovered upon review of all resections performed by 2 surgeons at the University of California, San Francisco between 2007 and 2014. Cervical tumor resections and resections for neurofibroma were excluded from this group of cases, as these were always performed via an open approach. In total, 51 resections were performed for thoracolumbar, intradural-extramedullary tumors. The surgical approach (minimally invasive surgery [MIS] vs open surgery) was performed at the discretion of the operating surgeon. Both surgeons perform both MIS and open tumor surgeries; in this series, one surgeon (P.V.M.) performed 24 minimally invasive and 15 open resections, and the other (D.C.) performed 1 minimally invasive resection and 11 open resections. After the appropriate institutional review board approval was obtained, patients' electronic medical records were reviewed for patient, operative, and postoperative characteristics. For the purposes of statistical analysis, American Spinal Injury Association (ASIA) scores were converted to numbers $(\mathrm{A}=1, \mathrm{~B}=2$, etc.), as described previously. Median preoperative ASIA scores are reported as they would be clinically, however. Postoperative ASIA scores were obtained at the patient's last follow-up visit. Tumor size in the craniocaudal direction was determined prior to surgery based on T1-weighted MR images. Extent of resection was determined on postoperative MR images.

\section{Surgical Technique}

The minimally invasive transspinous approach has been described previously. ${ }^{7,8}$ The primary surgeon decided on the surgical approach preoperatively. In brief, after informed consent was obtained, baseline somatosensory evoked potential and motor evoked potential monitoring was performed. This neuromonitoring was rechecked after the patient was flipped to the prone position. The surgical level was marked with the aid of lateral fluoroscopy. Through a 3- to 4-cm midline incision, the spinous processes were amputated at their base with a rongeur, and a Pipeline expandable retractor (DePuy Spine) was placed in the midline following sequential muscle dilation (Fig. 1). After the retractor was expanded, minimal tissue dissection was required. Single-level or multilevel laminectomies with undercutting of the lateral lamina were performed to provide excellent exposure.

A midline dural incision allowed for tumor resection using standard microsurgical techniques with the aid of an operative microscope. After the dura was closed with a running 4-0 Nurolon suture, a Valsalva maneuver was induced to detect any CSF leak. If a leak was detected, it was patched with muscle fascia autograft or Tisseel fibrin adhesive.

\section{Statistical Analysis}

All statistical operations were performed with SPSS

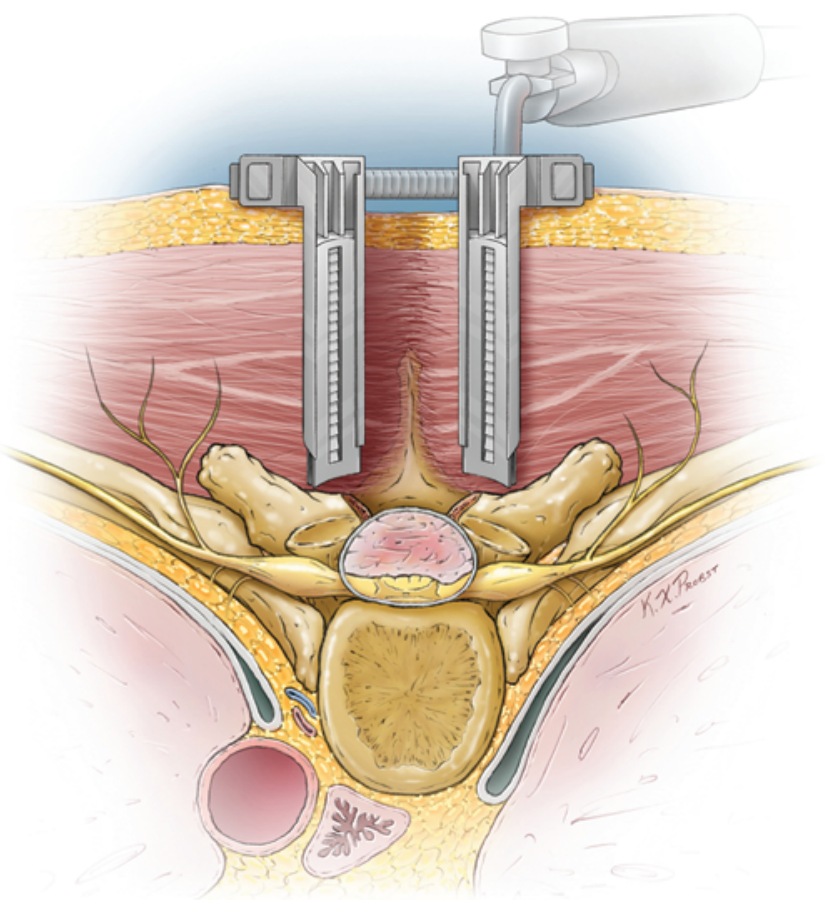

FIG. 1. Illustration of the minimally invasive transspinous approach for resection of intradural spinal tumors. A retractor with expandable and extendable blades that allows for adequate tissue retraction is shown. The approach allows excellent exposure of dorsally located intradural tumors. Reproduced from Lu et al: J Neurosurg Spine 14:758-764, 2011, with permission.

version 22 (IBM). Continuous variables were compared using parametric the Student t-test or nonparametric Mann-Whitney U-test after assessing for normality with the Shapiro-Wilk test. Categorical variables were compared with the Pearson chi-square or Fisher exact test, as appropriate. The threshold for statistical significance was set at a $p$ value of 0.05 .

\section{Results}

A similar number of minimally invasive $(n=25)$ and open $(\mathrm{n}=26)$ thoracolumbar, intradural-extramedullary tumor resections were performed between 2007 and 2014. The 2 groups were well matched; there were no statistically significant differences in patient characteristics, including age at surgery, sex, body mass index, preoperative ASIA score, preoperative symptom duration, procedure number, ASA physical status classification, tumor size, and tumor location (Table 1). The median preoperative ASIA score was E in the MIS group and D in the open group $(p=0.57)$. Two patients in the MIS cohort $(8 \%)$ and 1 in the open cohort (4\%) had previously undergone tumor resection at an outside hospital and came to our institution for management of tumor recurrence $(p=0.53)$. There were 8 thoracic, 4 thoracolumbar junction, 12 lumbar, and 1 lumbosacral tumors in the MIS group compared with 9 thoracic, 1 thoracolumbar junction, 12 lumbar, and 4 lumbosacral tumors in the open cohort $(\mathrm{p}=0.30)$. There was a nonsignificant trend for tumors in the MIS cohort to be smaller than those in the open cohort (mean $1.9 \pm 0.6 \mathrm{~cm}$ vs $3.0 \pm 2.9 \mathrm{~cm}, \mathrm{p}=0.07$ ). 
TABLE 1. Patient characteristics

\begin{tabular}{lccc}
\hline \multicolumn{1}{c}{ Variable } & $\begin{array}{c}\text { MIS } \\
\text { Approach }\end{array}$ & $\begin{array}{c}\text { Open } \\
\text { Approach }\end{array}$ & p Value \\
\hline Age (mean \pm SD) & $51.3 \pm 17.4$ & $51.7 \pm 15.9$ & 0.92 \\
\hline Sex (\% female) & 48.0 & 57.7 & 0.49 \\
\hline BMI (mean \pm SD) & $28.7 \pm 5.6$ & $27.6 \pm 4.8$ & 0.54 \\
\hline Preoperative ASIA score & $\mathrm{E}$ [B-E] & $\mathrm{D}[\mathrm{C}-\mathrm{E}]$ & 0.57 \\
$\quad$ (median [range]) & & & \\
\hline Preoperative Sx duration in & $12.5 \pm 15.5$ & $12.7 \pm 14.7$ & 0.98 \\
$\quad$ mos (mean \pm SD) & & & \\
\hline Previous surgery (\%) & 8.0 & 3.8 & 0.53 \\
\hline ASA classification (\%) & & & 0.40 \\
$\quad$ ASA 1 & 15.0 & 33.3 & \\
ASA 2 & 60.0 & 50.0 & \\
ASA 3 & 25.0 & 16.7 & \\
\hline Tumor size in cm (mean \pm SD) & $1.9 \pm 0.6$ & $3.0 \pm 2.9$ & 0.07 \\
\hline Tumor location (\%) & & & 0.30 \\
$\quad$ Thoracic & 32.0 & 34.6 & \\
Thoracolumbar junction & 16.0 & 3.8 & \\
Lumbar & 48.0 & 46.2 & \\
Lumbosacral & 4.0 & 15.4 & \\
\hline
\end{tabular}

$\mathrm{BMI}=$ body mass index; $\mathrm{Sx}=$ symptom(s).

\section{Operative Characteristics}

Features related to surgery were largely similar between the 2 cohorts (Table 2). The most common laminectomy performed in each group was an L1-2 laminectomy (16\% of MIS resections and 23\% of open resections), although the MIS resections tended to involve fewer levels $(\mathrm{p}<0.05)$. The 2 groups had comparable operative durations, but there was a statistically significant difference in mean estimated blood loss (EBL) $(142.0 \pm 99.7 \mathrm{ml}$ in the MIS group vs $320.0 \pm 407.9 \mathrm{ml}$ in the open group, $\mathrm{p}<$ $0.05)$. This EBL difference did not translate into a significant difference in the percentage of patients who required blood transfusions in the 2 cohorts (4\% of patients in the MIS group vs $12 \%$ in the open group, $\mathrm{p}=0.32$ ). The 2 cohorts had similar rates of gross-total resection $(92 \%$ in the MIS group vs $88.5 \%$ in the open group, $\mathrm{p}=0.67$ ) and surgery rarely resulted in significant loss of motor evoked potentials ( $0 \%$ of MIS cases vs $8 \%$ of open cases, $\mathrm{p}=0.49$ ). In each case of subtotal resection, tumor was firmly adherent to either the conus medullaris or functioning nerve roots, so the surgeon decided to leave a residual to minimize neurological deficits. The patient's functional status either remained at baseline or improved following surgery in each of those cases. Importantly, tumor excision was never halted, nor was the surgical technique ever converted to an open approach, as a result of limited exposure in the MIS cohort; however, 1 open resection was halted due to a significant loss of motor evoked potentials. No patient in the MIS group and 4 patients in the open group underwent spinal instrumentation $(\mathrm{p}<0.001)$. Three patients received pedicle screw fixation and fusion, although one had a preexisting L5-S1 spondylolysis and another had significant bony erosion of the sacrum necessitating fusion; the fourth patient underwent instrumented laminoplasty of the thoracic spine. Figure 2 demonstrates
TABLE 2. Operative characteristic

\begin{tabular}{lccl}
\hline \multicolumn{1}{c}{ Variable } & $\begin{array}{c}\text { MIS } \\
\text { Approach }\end{array}$ & $\begin{array}{c}\text { Open } \\
\text { Approach }\end{array}$ & p Value \\
\hline $\begin{array}{l}\text { Number of levels (median } \\
{[\text { IQR]) }}\end{array}$ & $2[2-2]$ & $2[2-3]$ & $0.048^{*}$ \\
\hline EBL in ml (mean \pm SD) & $142.0 \pm 99.7$ & $320.0 \pm 407.9$ & $0.039^{*}$ \\
\hline $\begin{array}{l}\text { Extent of resection (\% w/ } \\
\text { GTR) }\end{array}$ & 92.0 & 88.5 & 0.67 \\
\hline $\begin{array}{l}\text { Operative duration in mins } \\
\text { (mean } \pm \text { SD) }\end{array}$ & $188.9 \pm 40.0$ & $218.6 \pm 88.3$ & 0.19 \\
\hline $\begin{array}{l}\text { Significant loss of MEPs (\%) } \\
\text { Spinal instrumentation (\%) }\end{array}$ & 0 & & \\
\hline $\begin{array}{l}\text { Tumor pathology (\%) } \\
\text { Schwannoma }\end{array}$ & 0 & 15.4 & 0.49 \\
$\quad$ Meningioma & 40.0 & 38.4 & $0.00001^{*}$ \\
$\quad$ Ependymoma & 24.0 & 23.1 & \\
$\quad$ Other & 20.0 & 23.1 & \\
\hline GTR = gross total resection; IQR $=$ interquartile range; MEPs = motor evoked \\
potentials. \\
* Statistically significant.
\end{tabular}

representative pre- and postoperative imaging for a patient in the MIS cohort. The 3 most common tumor pathologies in each group were schwannoma, meningioma, and ependymoma $(\mathrm{p}=0.99)$.

\section{Postoperative Characteristics}

During a mean follow-up of 2 years in the MIS cohort and 1.6 years in the open group $(\mathrm{p}=0.34)$, the overall recurrence rates were equivalent (4\% each). For a comparison of all postoperative characteristics, see Table 3 . The MIS cohort had a greater improvement in functional status after surgery as determined by mean change in ASIA score, but the difference between the 2 cohorts was not statistically significant $(\mathrm{p}=0.09)$. There were no differences in overall length of stay (LOS) $(p=0.73)$, although there was a trend for patients in the MIS group to have fewer postoperative adverse events (with AEs occurring in $8 \%$ of the patients in the MIS group vs $19 \%$ of those in the open surgery group, $p=0.24$ ). Adverse events in the MIS cohort included 1 pseudomeningocele and 1 pulmonary embolus; whereas those in the open cohort included 3 CSF leaks, 1 subfascial wound infection, and 1 epidural hematoma. The 3 CSF leaks resolved after lumbar drain placement. The pseudomeningocele, subfascial wound infection, and epidural hematoma each required return to the operating room. In each case, functional status either improved or remained at baseline.

\section{Sensitivity Analyses}

Because those patients treated with open resection were more likely to have large tumors and were more likely to have more extensive laminectomies, we performed a sensitivity analysis to account for this bias. To do this, we repeated our analyses for small tumors only $(\leq 2 \mathrm{~cm})$. The MIS and open subgroups included an equal number of patients (13 in each). There were no statistically significant differences in any pre-, intra-, or postoperative characteristics (Table 4); however, there was a statistically 

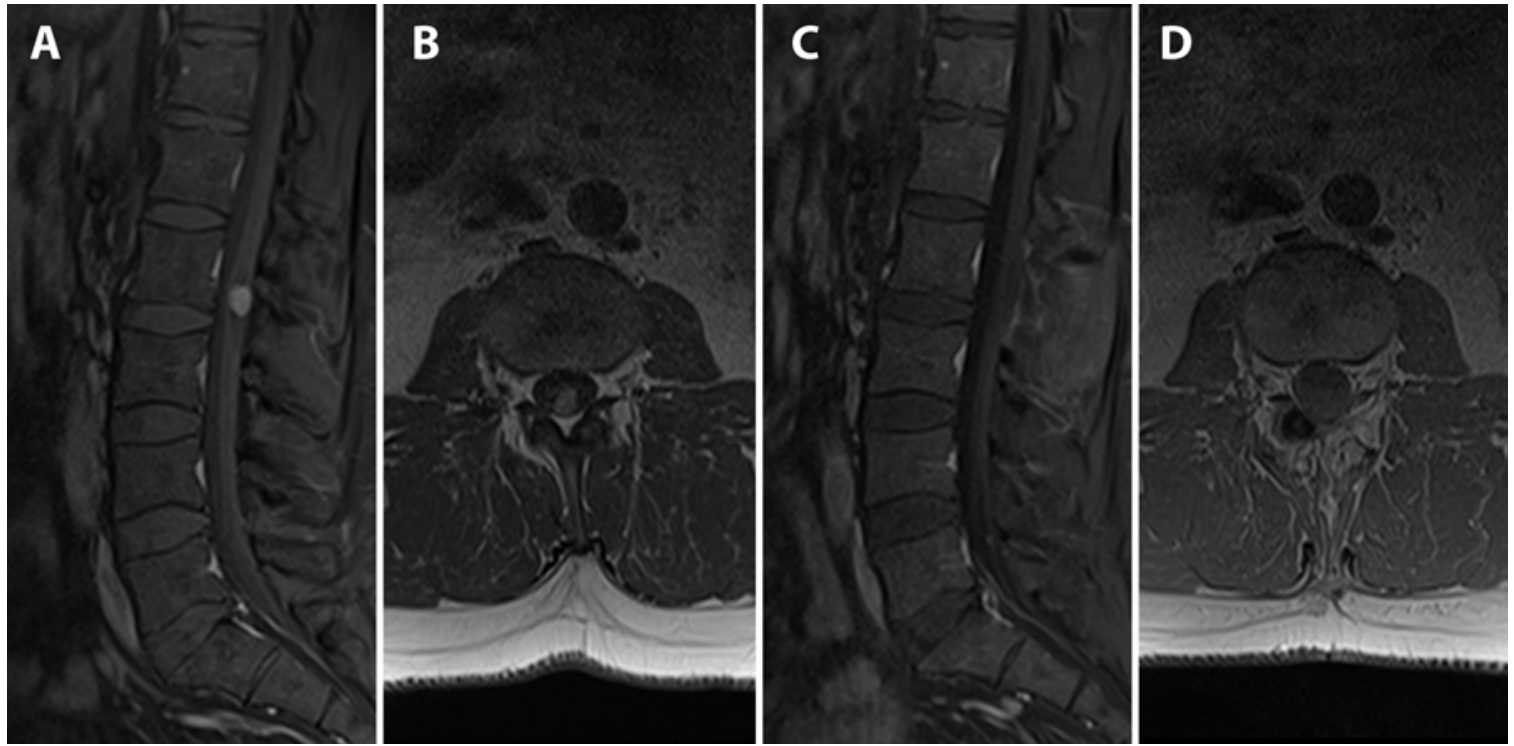

FIG. 2. Representative pre- and postoperative MR images from a representative patient who underwent minimally invasive transspinous tumor resection. A and B: Preoperative sagittal (A) and axial (B) T1-weighted MR images obtained after contrast administration demonstrating a homogeneously enhancing dorsal, intradural-extramedullary spinal tumor (schwannoma). $\mathrm{C}$ and D: Postoperative sagittal (C) and axial (D) T1-weighted MR images obtained after contrast administration demonstrating grosstotal resection of the tumor.

nonsignificant trend for the MIS cohort to have lower EBL values $(\mathrm{p}=0.06)$. Importantly, there were no statistically significant differences in adverse events between the MIS and open groups.

Additionally, because the 2 surgeons performed different proportions of MIS and open cases, we performed a sensitivity analysis in which only surgeries performed by a single surgeon (P.V.M.) were included (Table 5). Study characteristics were compared between the MIS and open cohorts as described earlier. As with the primary results, the major statistically significant differences between the 2 groups involved EBL (mean $139.6 \pm 101.1 \mathrm{ml}$ for MIS vs $446.7 \pm 491.2 \mathrm{ml}$ for open, $\mathrm{p}<0.05$ ) and the number of laminectomy levels (median 2 [IQR 2-2] vs 3 [2-3], p $<0.05)$.

\section{Discussion}

Intradural-extramedullary spinal tumors constitute nearly $80 \%$ of all primary spinal cord tumors..$^{15}$ The majority of these lesions are benign, and patients have had excellent outcomes following complete surgical excision. Over the years, however, surgeons have improved upon the standard, open laminectomy approach with open hemilaminectomy and minimally invasive techniques. The

TABLE 3. Postoperative characteristics

\begin{tabular}{lccc}
\hline \multicolumn{1}{c}{ Variable } & $\begin{array}{c}\text { MIS } \\
\text { Approach }\end{array}$ & $\begin{array}{c}\text { Open } \\
\text { Approach }\end{array}$ & p Value \\
\hline Recurrence (\%) & 4.0 & 3.8 & 0.98 \\
\hline Adverse events (\%) & 8.0 & 19.2 & 0.24 \\
\hline Change in ASIA score (mean \pm SD) & $0.4 \pm 0.7$ & $0.0 \pm 0.7$ & 0.09 \\
\hline LOS in days (mean \pm SD) & $6.9 \pm 1.8$ & $7.2 \pm 3.0$ & 0.73 \\
\hline Follow-up in yrs (mean \pm SD) & $2.0 \pm 1.6$ & $1.6 \pm 1.6$ & 0.34 \\
\hline
\end{tabular}

open hemilaminectomy approach gained favor because it yielded comparable outcomes without the spinal instability occasionally seen following removal of the posterior spinous elements. ${ }^{1,2,12,13,17}$ More recently, minimally invasive approaches using either midline or paramedian incisions and either expandable or nonexpandable tubular retractors have been proposed for spinal tumor resection.

Prior studies examining the safety and efficacy of various minimally invasive techniques for intradural tumor resection have been limited to case series with historical controls, ${ }^{4,8,9,11,16}$ with the exception of 1 prior retrospective cohort study? The data presented here represent the largest direct comparison of traditional, open approaches with the minimally invasive transspinous approach using a Pipeline retractor system.

Based on our results, the MIS transspinous approach appears to be at least as safe and effective as standard, open laminectomy techniques. Using well-matched cohorts, we demonstrate equivalent extent of resection, operative duration, hospital LOS, and recurrence rates, although the MIS cohort had significantly reduced intraoperative blood loss and showed a trend toward larger improvements in functional outcome (as measured by the ASIA score) compared with the open cohort. Five subtotal resections were performed between the 2 groups ( 2 MIS and 3 open). We suspect that the slightly lower gross-total resection rate in the open cohort was related to the larger tumors in that group (see Table 2).

In addition to the sensitivity analyses described earlier, 2 additional analyses were performed to confirm our findings related to EBL and LOS. The large standard deviation seen for EBL in the open cohort was caused by 2 patients, who had EBLs of $1 \mathrm{~L}$ and $2 \mathrm{~L}$. Even when these 2 patients were excluded from the analysis, the mean EBL in the MIS group (142.0 $\pm 99.7 \mathrm{ml})$ was statistically significantly 
TABLE 4. Sensitivity analysis comparing preoperative, operative, and postoperative characteristics in patients with small tumors $(\leq 2 \mathrm{~cm})$

\begin{tabular}{|c|c|c|c|}
\hline Variable & $\begin{array}{c}\text { MIS } \\
\text { Approach }\end{array}$ & $\begin{array}{l}\text { Open } \\
\text { Approach }\end{array}$ & $\mathrm{p}$ Value \\
\hline \multicolumn{4}{|l|}{ Preoperative } \\
\hline Age in yrs (mean \pm SD) & $53.3 \pm 16.4$ & $62.5 \pm 11.7$ & 0.11 \\
\hline Sex (\% female) & 23.1 & 30.8 & 0.42 \\
\hline BMI (mean \pm SD) & $28.8 \pm 5.8$ & $29.3 \pm 5.2$ & 0.82 \\
\hline $\begin{array}{l}\text { Preoperative ASIA score } \\
\text { (median [range]) }\end{array}$ & $E[B-E]$ & $E[D-E]$ & $>0.99$ \\
\hline $\begin{array}{l}\text { Preoperative Sx duration in } \\
\text { mos (mean } \pm \text { SD) }\end{array}$ & $15.5 \pm 19.5$ & $12.8 \pm 16.2$ & 0.71 \\
\hline Previous surgery (\%) & 0 & 0 & - \\
\hline ASA classification (\%) & & & 0.63 \\
\hline ASA 1 & 16.7 & 11.1 & \\
\hline ASA 2 & 58.3 & 77.8 & \\
\hline ASA 3 & 25.0 & 11.1 & \\
\hline $\begin{array}{l}\text { Tumor size in } \mathrm{cm} \text { (mean } \pm \\
\text { SD) }\end{array}$ & $1.5 \pm 0.5$ & $1.3 \pm 0.4$ & 0.26 \\
\hline Tumor location (\%) & & & 0.17 \\
\hline Thoracic & 23.1 & 46.2 & \\
\hline Thoracolumbar junction & 23.1 & 0 & \\
\hline Lumbar & 46.2 & 53.8 & \\
\hline Lumbosacral & 7.6 & 0 & \\
\hline \multicolumn{4}{|l|}{ Operative } \\
\hline No. of levels (median [IQR]) & $2[2-2]$ & $2[2-2]$ & 0.58 \\
\hline $\mathrm{EBL}$ in $\mathrm{ml}$ (mean $\pm \mathrm{SD})$ & $115.4 \pm 62.5$ & $212.5 \pm 165.3$ & 0.06 \\
\hline EOR (\% w/ GTR) & 92.3 & 92.3 & $>0.99$ \\
\hline $\begin{array}{l}\text { Operative duration in mins } \\
\quad(\text { mean } \pm \text { SD) }\end{array}$ & $176.3 \pm 37.5$ & $167.7 \pm 42.7$ & 0.62 \\
\hline Significant loss of MEPs (\%) & 0 & 7.7 & 0.31 \\
\hline Spinal instrumentation (\%) & 0 & 7.7 & 0.31 \\
\hline Pathology (\%) & & & 0.19 \\
\hline Schwannoma & 53.8 & 46.1 & \\
\hline Meningioma & 23.1 & 15.4 & \\
\hline Ependymoma & 15.4 & 15.4 & \\
\hline Other & 7.7 & 23.1 & \\
\hline \multicolumn{4}{|l|}{ Postoperative } \\
\hline Recurrence (\%) & 0 & 0 & - \\
\hline Adverse events (\%) & 7.7 & 7.7 & $>0.99$ \\
\hline $\begin{array}{l}\text { Change in ASIA (mean } \pm \\
\text { SD) }\end{array}$ & $0.5 \pm 0.9$ & $0.0 \pm 0.6$ & 0.13 \\
\hline LOS in days (mean \pm SD) & $6.8 \pm 1.8$ & $6.9 \pm 3.0$ & 0.94 \\
\hline $\begin{array}{l}\text { Follow-up in yrs (mean } \pm \\
\text { SD) }\end{array}$ & $1.8 \pm 1.1$ & $1.2 \pm 1.1$ & 0.13 \\
\hline
\end{tabular}

$E O R=$ extent of resection.

lower than in the open group $(217.4 \pm 145.9 \mathrm{ml}, \mathrm{p}<0.05)$. The precise clinical relevance of this difference in EBL is not immediately clear, given that only 4 patients in our cohort (1 in the MIS group and 3 in the open group) actually required blood transfusions. Studies with larger sample sizes will likely be needed to prove a clinical benefit.

An additional sensitivity analysis was performed for the
TABLE 5. Sensitivity analysis comparing preoperative, operative, and postoperative characteristics from the surgical series of one surgeon (P.V.M.)

\begin{tabular}{|c|c|c|c|}
\hline Variable & $\begin{array}{c}\text { MIS } \\
\text { Approach }\end{array}$ & $\begin{array}{c}\text { Open } \\
\text { Approach }\end{array}$ & $p$ Value \\
\hline \multicolumn{4}{|l|}{ Preoperative } \\
\hline Age in yrs (mean \pm SD) & $50.7 \pm 17.5$ & $50.9 \pm 16.6$ & 0.97 \\
\hline Sex ( $\%$ female) & 50.0 & 46.7 & 0.42 \\
\hline BMI (mean \pm SD) & $28.8 \pm 5.7$ & $27.8 \pm 4.7$ & 0.65 \\
\hline $\begin{array}{l}\text { Preoperative ASIA score } \\
\text { (median [range]) }\end{array}$ & $E[B-E]$ & $\mathrm{D}[\mathrm{C}-\mathrm{E}]$ & 0.54 \\
\hline $\begin{array}{l}\text { Preoperative Sx duration in } \\
\text { mos (mean } \pm \text { SD) }\end{array}$ & $12.4 \pm 15.9$ & $10.1 \pm 13.4$ & 0.63 \\
\hline Previous surgery (\%) & 8.3 & 0 & 0.25 \\
\hline $\begin{array}{l}\text { ASA classification (\%) } \\
\text { ASA } 1 \\
\text { ASA } 2 \\
\text { ASA } 3\end{array}$ & $\begin{array}{l}15.8 \\
57.9 \\
26.3 \\
\end{array}$ & $\begin{array}{l}35.7 \\
50.0 \\
15.3\end{array}$ & 0.38 \\
\hline $\begin{array}{l}\text { Tumor size in } \mathrm{cm} \text { (mean } \pm \\
\text { SD) }\end{array}$ & $1.8 \pm 0.6$ & $3.5 \pm 3.7$ & 0.11 \\
\hline $\begin{array}{l}\text { Tumor location (\%) } \\
\text { Thoracic } \\
\text { Thoracolumbar junction } \\
\text { Lumbar } \\
\text { Lumbosacral }\end{array}$ & $\begin{array}{r}33.3 \\
16.7 \\
45.8 \\
4.2\end{array}$ & $\begin{array}{c}33.3 \\
0 \\
40.0 \\
26.7\end{array}$ & 0.10 \\
\hline \multicolumn{4}{|l|}{ Operative } \\
\hline No. of levels (median [IQR]) & $2[2,2]$ & $3[2,3]$ & $0.004^{*}$ \\
\hline $\mathrm{EBL}$ in $\mathrm{ml}$ (mean $\pm \mathrm{SD})$ & $139.6 \pm 101.1$ & $446.7 \pm 491.2$ & $0.03^{*}$ \\
\hline EOR (\% w/ GTR) & 91.7 & 80.0 & 0.29 \\
\hline $\begin{array}{l}\text { Operative duration in mins } \\
\quad(\text { mean } \pm S D)\end{array}$ & $192.4 \pm 44.1$ & $231.9 \pm 94.9$ & 0.16 \\
\hline Significant loss of MEPs (\%) & 0 & 13.3 & 0.07 \\
\hline Spinal instrumentation (\%) & 0 & 20.0 & $0.02^{*}$ \\
\hline $\begin{array}{l}\text { Pathology (\%) } \\
\text { Schwannoma } \\
\text { Meningioma } \\
\text { Ependymoma } \\
\text { Other }\end{array}$ & $\begin{array}{l}37.5 \\
25.0 \\
20.8 \\
16.7\end{array}$ & $\begin{array}{l}40.0 \\
26.7 \\
20.0 \\
13.3\end{array}$ & 0.99 \\
\hline \multicolumn{4}{|l|}{ Postoperative } \\
\hline Recurrence (\%) & 4.2 & 6.7 & 0.73 \\
\hline Adverse events (\%) & 8.3 & 13.3 & 0.62 \\
\hline $\begin{array}{l}\text { Change in ASIA (mean } \pm \\
\text { SD) }\end{array}$ & $0.4 \pm 0.7$ & $0.2 \pm 0.7$ & 0.45 \\
\hline LOS in days (mean $\pm \mathrm{SD}$ ) & $7.0 \pm 1.8$ & $7.1 \pm 2.4$ & 0.92 \\
\hline $\begin{array}{l}\text { Follow-up in yrs (mean } \pm \\
\text { SD) }\end{array}$ & $2.0 \pm 1.7$ & $1.3 \pm 1.6$ & 0.23 \\
\hline
\end{tabular}

* Statistically significant.

comparison of LOS between the 2 cohorts. Six patients in the MIS cohort and 10 in the open cohort were directly admitted to the hospital; on average, these patients spent 3.0 and 2.9 days, respectively, in the hospital prior to having surgery. When these preoperative hospital days were excluded from the analysis, the postoperative LOS was equivalent in the 2 groups $(6.2 \pm 1.6$ days vs $6.0 \pm 2.4$ days, 
$p=0.78)$. Nevertheless, the average LOS in our patient cohort is longer than the approximately 3 days described in previous studies. ${ }^{4,9,11,16}$ We believe this prolonged LOS is related to postoperative pain. At our institution, most patients use a patient-controlled analgesia device for the first 24 hours after surgery after which they are weaned to an appropriate outpatient pain control regimen. In at least 1 patient in the MIS cohort, postoperative narcotics use totaled $160 \mathrm{mg}$ in oral morphine equivalents, which is significantly greater than the average of $66.3 \mathrm{mg}$ described by Nzokou and colleagues. ${ }^{11}$ Future studies should examine postoperative narcotics use, both to explain prolonged LOS and to determine whether MIS techniques affect immediate postoperative pain.

Although we prefer the minimally invasive transspinous approach using a midline incision, we understand its limitations. In our cohort, the tumors exposed and the laminectomies performed in the MIS cohort tended to be smaller than those in the open cohort, although tumor size was not statistically significantly different in the 2 groups. This selection bias, combined with the fact that 4 patients in the open group and none in the MIS group underwent placement of instrumentation, likely reflected the surgeons' clinical experience that tumors spanning more than 2 segments could not be optimally managed via an MIS approach. Thus, we feel that this MIS technique is better suited for small tumors involving no more than 2 levels and without significant extraforaminal extension. Patients with lateral tumor extension, bony erosion, or other findings seen on preoperative imaging that suggest the need for fusion are currently not ideal candidates for the MIS approach. In addition, conversion to an open approach may be necessary for patients with intraoperative findings requiring instrumentation. Importantly, the sensitivity analysis performed on patients with small tumors re-demonstrated a trend toward lower EBL in the MIS cohort (Table 4). We hypothesize that a statistically significant difference in EBL was not reached because of the relatively small sample sizes used in this sensitivity analysis. Thus, even when accounting for this selection bias, the MIS technique is safe and effective. In addition, the potential for surgeon bias was mitigated by the fact that additional analyses performed after excluding surgeries by D.C. (which were mostly done through an open approach) recapitulated our primary results (Table 5). Although we prefer the transspinous approach due to its exposure of the entire dorsal spinal cord, MIS hemilaminectomy techniques with paramedian incisions can avoid midline scar tissue in patients who have had previous surgery and may thus be beneficial in those circumstances.

While this study is one of the largest comparisons of MIS and open techniques for intradural tumor resection, as with any retrospective review, the analyses are open to bias. We minimized the effects of selection bias by including consecutive thoracolumbar, extramedullary tumor resections between 2007 and 2014 and were reassured by how well matched the 2 groups were. Although a selection bias existed for larger tumors to be resected via an open approach, we believe that the minimally invasive transspinous technique is as safe and effective as open techniques for small tumors spanning 2 segments or fewer.
Unaccounted differences between the 2 surgeons appear to not be significant based on our sensitivity analysis. Still, to definitively demonstrate comparative efficacy of this approach and to determine optimal patient eligibility criteria, a prospective randomized controlled trial should be performed. Such trials should include comparisons of validated patient-reported quality of life measures, postoperative narcotics usage, postoperative intensive care unit requirements, and overall costs.

\section{Conclusions}

The minimally invasive transspinous approach to intradural-extramedullary tumor resection is as safe and effective as standard, open approaches, with the advantage of reduced intraoperative blood loss. Future prospective, randomized studies aimed at directly comparing minimally invasive techniques and determining the cost effectiveness of those techniques may influence their adoption by other surgeons.

\section{References}

1. Alexander E Jr: Postlaminectomy kyphosis, in Wilkins RH, Rengachary SS (eds): Neurosurgery. New York: McGrawHill, 1985, pp 2293-2297

2. Chiou SM, Eggert HR, Laborde G, Seeger W: Microsurgical unilateral approaches for spinal tumour surgery: eight years' experience in 256 primary operated patients. Acta Neurochir (Wien) 100:127-133, 1989

3. Fogelholm R, Uutela T, Murros K: Epidemiology of central nervous system neoplasms. A regional survey in Central Finland. Acta Neurol Scand 69:129-136, 1984

4. Haji FA, Cenic A, Crevier L, Murty N, Reddy K: Minimally invasive approach for the resection of spinal neoplasm. Spine (Phila Pa 1976) 36:E1018-E1026, 2011

5. Kurland LT: The frequency of intracranial and intraspinal neoplasms in the resident population of Rochester, Minnesota. J Neurosurg 15:627-641, 1958

6. Levy WJ, Latchaw J, Hahn JF, Sawhny B, Bay J, Dohn DF: Spinal neurofibromas: a report of 66 cases and a comparison with meningiomas. Neurosurgery 18:331-334, 1986

7. Lu DC, Chou D, Mummaneni PV: A comparison of miniopen and open approaches for resection of thoracolumbar intradural spinal tumors. J Neurosurg Spine 14:758-764, 2011

8. Lu DC, Dhall SS, Mummaneni PV: The transspinous miniopen approach for resection of intradural spinal neoplasms: cadaveric feasibility study and report of 3 clinical cases. World Neurosurg 74:195-199, 2010

9. Mannion RJ, Nowitzke AM, Efendy J, Wood MJ: Safety and efficacy of intradural extramedullary spinal tumor removal using a minimally invasive approach. Neurosurgery 68 (1 Suppl Operative):208-216, 2011

10. Newton HB, Newton CL, Gatens C, Hebert R, Pack R: Spinal cord tumors: review of etiology, diagnosis, and multidisciplinary approach to treatment. Cancer Pract 3:207-218, 1995

11. Nzokou A, Weil AG, Shedid D: Minimally invasive removal of thoracic and lumbar spinal tumors using a nonexpandable tubular retractor. J Neurosurg Spine 19:708-715, 2013

12. Oktem IS, Akdemir H, Kurtsoy A, Koç RK, Menkü A, Tucer B: Hemilaminectomy for the removal of the spinal lesions. Spinal Cord 38:92-96, 2000

13. Sario-glu AC, Hanci M, Bozkuş H, Kaynar MY, Kafadar A: Unilateral hemilaminectomy for the removal of the spinal space-occupying lesions. Minim Invasive Neurosurg 40:74-77, 1997 
14. Sloof J, Kernohan J, MacCarthy C: Primary Intramedullary Tumors of the Spinal Cord and Filum Terminale. Philadelphia: Saunders, 1964

15. Stein BM, McCormick PC: Spinal intradural tumors, in Wilkins RH, Rengachary SS (eds): Neurosurgery, ed 2. New York: McGraw-Hill, 1996, pp 1769-1781

16. Tredway TL, Santiago P, Hrubes MR, Song JK, Christie SD, Fessler RG: Minimally invasive resection of intraduralextramedullary spinal neoplasms. Neurosurgery 58 (1 Suppl):ONS52-ONS58, 2006

17. Yaşargil MG, Tranmer BI, Adamson TE, Roth P: Unilateral partial hemi-laminectomy for the removal of extra- and intramedullary tumours and AVMs. Adv Tech Stand Neurosurg 18:113-132, 1991

\section{Author Contributions}

Conception and design: all authors. Acquisition of data: Raygor. Analysis and interpretation of data: Raygor. Drafting the article: Raygor. Critically revising the article: all authors. Reviewed submitted version of manuscript: all authors. Approved the final version of the manuscript on behalf of all authors: Mummaneni. Statistical analysis: Raygor. Study supervision: Mummaneni.

\section{Correspondence}

Praveen V. Mummaneni, Department of Neurological Surgery, University of California, San Francisco, 505 Parnassus Ave., M779, San Francisco, CA 94143-0112.email: mummanenip@ neurosurg.ucsf.edu. 